\begin{abstract}
INFANCLA Y APRENDIZAJE
En el panorama editorial del año 1978 aparece la revista «lnfancia y aprendizajen, a iniciativa de un grupo de psicollogos de Madrid, con el objetivo de cubrir el espacio de información destinado al conjunto de profesionales vinculados o interesados en la enseflanza, (psicólogos, pedagogos, educadores, estudiantes, profesorado, etc...)

Actualmente la revista cuenta ya con veinte números publicados y ofrece un cuerpo teórico-práctico en torno a las orientaciones principales en investigación educativa, así como descripciones del funcionamiento de las distintas instituciones relacionadas con la ensenan. 2a, informacion de congresos, etc.

Los trabajos publicados tratan sobre te
\end{abstract}

mas de psicología del desarrollo y psicopectagogia, dándose preferencia a investigaciones y aplicaciones experimentales y a modos de exposición precisos.

Los ejes esenciales que constituyen el bagaje temático de los trabajos publicados se concretan en: metodologla, psicologia educativa, educación especial, desarrollo cognitivo, afectivo y social, desarrollo neuropsicologico, etc...) Entre el contenido especifico de estos temas podemos seffalar algunos trabajos que aportan información sobre aspectos relacionados con la enseffanza de las ciencias, taies como:

- sobre el desarrollo cognitivo: Carre. tero, (1979), (1980), Gillieron (1980), Giordan, (1981), Gomez, (1981), Karmiloff-Smith, Inhelder, (1981)... - sobre psicologia escolar y educati- va: Brun (1980), Delval (1981), Gilly (1980), Moreno (1980), PerretClermont (1980), Coll (1980), Huteau (1980)...

- Informes de distintas instituciones o grupos sobre planes de actuación en algunas zonas $y$ las correspondientes investigaciones realizadas: Equipo de Psicologia de San Juan de Dios (1980), Sección del Colegio de Psicólogos de Madrid (1980), y de Barcelona (1980). Grupo de lnvestigaciones psicupedagógicas (1980), IMIPAE (1979), Grupo Rapsodie (1981).

Para cualquier información dirigirse a:

INFANCIA Y APRENDIZAJE

Siglo XXI

c/ PLaza, 5 - Madrid 33

NURIa SALO

\title{
TESIS Y TESINAS SOBRE DIDACTICA DE LAS CIENCIAS
}

Son bien conocidas las dificullades encontradas por quienes desean investigar sobre problemas de didáctica de las ciencias $y$ mas concretamente, presentar tesis de doctorado o incluso de licenciatura. Ello es debido a un conjunto de causas como la falta absoluta de rradición de nuestros centros educativos en investigación didáctica, las dificultades administrativas, etc., sin olvidar la escasa calidad -en parte justificada por la misma ausencia de tradición-de bastantes de los trabajos presentados. Pero se trata de una situación que empieza a cambiar y a cuya superación "Ensenanza de las Ciencias" quiere contribuir dando a conocer aquellas resis y tesinas que se han presentado o vayan presentándose en el futuro. Hacemos, pues, una llamada a rodos los interesados para que den a conocer sus trabajos. Para ello bosto con enviar un resumen de la tesis o tesino en un máximo de dos folios a doble espacio, con indicacion de: Titulo, Autor, Director, Ponente (si es distinto del Director), fecha y Iugar de presentación. Debe remitirse también fotocopia acreditativa de la presentación del trabajo y, a ser posible, una copia del mismo.

\section{TESIS DE LICENCIATURA}

Títuio: Los errores conceptuales en la enselianza de las ciencias.

Autor: Jaime Corrascoso Alís, Profe. sor en el I.B. Cid Campeador de Valencia.

Fecha: Junio de 1982.

Lugar de presentación: Facultad de Quimicas de la Universidad de Valencia.

Esta tesis de licenciatura es el resultado del trabajo que nos planteamos después de consultar y estudiar numerosos artículos en diversas revistas de di. dáctica de las ciencias en donde se hacla referencia al grave problema de los errores conceptuaies cometidos por ele- vados porcentajes de alumnos, y que afectan a muchos conceptos fundamentales. Dichos errores se hallan presen. tes incluso entre jos estudiantes universitarios de ciencias y tambien en parte del propio profesorado de dicha área.

Partiendo de esta situación, se comienza por el planteamiento de dos cuestiones:

$1^{2}$ ¿Cuales son las causas de la gran abundancia y persistencia de los errores conceptuales entre los alumnos?

$2^{*}$ ¿De qué forma podría conseguirse una drástica disminución de su presencia en los distintos niveles educativos?
El dar respuesta a la primera de las cuestiones planteadas, constituye principalmente toda la primera parte de la tesina. Para ello se comienza por enunciar una primera hipótesis, según la cual la gran abundancia y persistencia de los errores conceptuales entre e! alumnado, se debe principaimente a incorrectos planteamientos didácticos, que se traducen principalmente en:

A No tener en cuenta la estructura cognoscitiva del alumuado y la consiguiente necesidad de que los nue. vos conocimientos se integren en ella.

B Una enseftanza con una metodologia que no incide sensiblemente en la tendencia habitual de los alum- 
nos a sacar conclusiones precipitadas y a hacer generalizaciones prematuras sin una previa reflexion cr. tica sobre el problema que se le presente.

A continuación se procede a fundamentar teóricamente la hipótesis anterior utilizando para ello los resultados y las opiniones que al respecto se dan en di. versos trabajos sobre epistemologia genética y psicologia educativa. Después se exponen los diseños experimentales para la contrastación de la hipótesis; diseţos que van desde la elaboración de cuestionarios ad hoc, al análisis de tex. tos de uso actual. For último se extraen unas primeras conclusiones sobre los resultados obtenidos.

En cuanto a la segunda cuestión, ésta viene tratada en la segunda parte del trabajo. Aqui tambien se comienza por enunciar una hipotesis, consistente esta vez en afirmar que si queremos reducir significativamente los errores conceptuales entre el alumnado, debemos utilizar una metodología didáctica que reproduzca en la enseñanza de las cien. cias los aspectos más importantes que en general tienen los trabajos de investigación cientifica. En lo que sigue de la tesina, se trata de la operativizacion de esta segunda hipotesis de cara a su contrastación experimental, asi como de su fundamentación teórica. Ello supone un detenido análisis de las caracterfsticas esenciales del proceso de investigacion científica y de sus implica. ciones en una enseñanza que pretenda ser coherente con dicho proceso.

A continuación se presenta un diseño experimental concebido como obtención de unos primeros resultados, que nos permitieran continuar por el camino iniciado. En efecto, como se muestra en la tesina, los resultados obtenidos parecen confirmar ampliamente la hipótesis. Actualmente estamos ampliando y profundizando este trabajo de cara a elaborar una tesis de doctorado.

\section{TESI DE LLICENCIATURA}

Titol: Els Treballs Prdctics de Biologia $i$ el Mètode Científic

Aulor: Anno M. Gené i Duch, professora de Didactica de ies Ciències Naturais de l'Escola Universitaria de Formació del Professorat de Lieida.

Data: 22 de setembre de 1982 .

Lloc de presentació: Facultat de BioJogia de la Universitat de Barcelona.
Quan fan referència als objectius bàsics de l'ensenyament de les Ciencies i concretament de la Biologia, els organismes nacionals $\mathrm{j}$ internacionals dedicats a l'educació, consideren primordial que els alumnes aprenguin la metodologia que eis cientifics utilizzen per a elaborar coneixements, com eina fonamental per a poder fer ciència i també per a desenvolupar el pensament formal.

El nostre treball mostra - a partir de resultats obtinguts de qüestionaris passats a alumnes, professors en exercici $i$ en formació aixi com de l'anàlisis de llibres de text i pràctiques de laboratori-que els treballs pràctics de biologia realizzats peis alumnes de tots els nivells de l'ensenyament no contribueixen a familiaritzar-los de forma significativa amb la metodologia cientifica.

Es donen també en aquest treball uns primers resultats comparatius, que mostren fins a quin punt la utilització d'un mètode d'ensenyament fonamentat en la metodologia cientifica l'aprenentatge per redescobriment dirigit - no solament contribueix a la familiarització amb el procès cientific de construccio de coneixements, sind també a l'aprenentatge significatiu dels mateixos.

\section{RESEÑAS DE CONGRESOS Y JORNADAS}

GRUPO DE TRABAJO DE HISTORIA Y EPISTEMOLO. GIA DE LA GEOLOGIA

Primeras Jornadas, Madrid 25-26 Febrero 1983

Con la colaboración del Instituto de Historia de las Ciencias (S.E.H.C.) y el Seminario de Historia de Aragón (SHCTAR) tuvieron lugar los dias 25 y 26 de Febrero de 1983 las primeras Jornadas del Grupo de Trabajo de Historia y Epistemologia de la Geologia. Han asistido 40 participantes.

Tras la apertura de las Jornadas a cargo del Sr. Decano de la Facultad de Geologia, Dr. José Luis Amorós, tuvo lugar la primera sesion: «Estado actual del conocimiento e investigación de la Historia de la Geologla en Espanan. Se habian presentado tres ponencias:
J.L. Amorós: «La mineralogía española: planteamiento de su estudion. L. Solé Sabaris: «Nueva orientación epistemológica en la Historia de la Geo. logia españolas.

Vicente Sos Baynat: «Los geólogos y la Institución Libre de Ensenanzay.

En la discusion de las ponencias se insistio en los puntos siguientes:

1. La Historia de la Geologia espanola, en especial la del siglo XIX, es un tema apasionante debido a la tradición cientifica, al alto nivel de los geólogos españoles en esta época y a su activa participación en la vida política de entonces.

2. Sin embargo son muy escasos los es. tudios sistematizados y profundos de ia Historia de la Geologla espanola, en particular del siglo XIX. Por ello este Grupo debe tener como tarea priorita- ria la investigacion de la procucción científica geoiógica en la Espana del XIX.

3. Dadas las conexiones de este tema con la Historia social y politica, asi como con aspectos filosóficos, se insistio en la necesidad de que el trabajo sea interdisciplinar.

4. Más en concreto, parece que una línea de trabajo debe ser diseñar y definir las distintas generaciones de geologos en este pertodo, las incidencias de otros geólogos extranjeros sobre ellos y su presencia en el mundo cientifico.

La segunda sesión trató sobre «El estado actual del conocimiento $e$ investigación de la Historia de la Geologfa y en el mundor.

La ponencia, a cargo de Leandro Sequeiros de la Universidad de Zaragoza, tuvo como misión informar sobre 